Supporting Information

\title{
Novel organic-inorganic perovskite compounds having phosphonium groups
}

Shunsuke SHIMIZU, Masahiro YOSHIZAWA-FUJITA, Yuko TAKEOKA* and Masahiro RIKUKAWA

Faculty of Science and Engineering, Sophia University, 7-1 Kioi-cho, Chiyoda-ku, Tokyo, 1028554, Japan.

Corresponding Author

*E-mail: y-tabuch@sophia.ac.jp 


\section{XRD profiles}

Figure $\mathrm{S} 1$ shows out-of-plane $\mathrm{XRD}$ profiles of $\mathrm{C}_{6} \mathrm{TN}-\mathrm{PbBr}, \mathrm{C}_{6} \mathrm{TP}-\mathrm{PbBr}$ and their precursor $\mathrm{C}_{6} \mathrm{TNBr}, \mathrm{C}_{6} \mathrm{TPBr}$ and $\mathrm{PbBr}_{2}$ films. $\mathrm{C}_{6} \mathrm{TN}-\mathrm{PbBr}$ and $\mathrm{C}_{6} \mathrm{TP}-\mathrm{PbBr}$ films showed different peaks from $\mathrm{C}_{6} \mathrm{TNBr}, \mathrm{C}_{6} \mathrm{TPBr}$, and $\mathrm{PbBr}_{2}$, suggesting that new structure was formed by complexation.

(a)

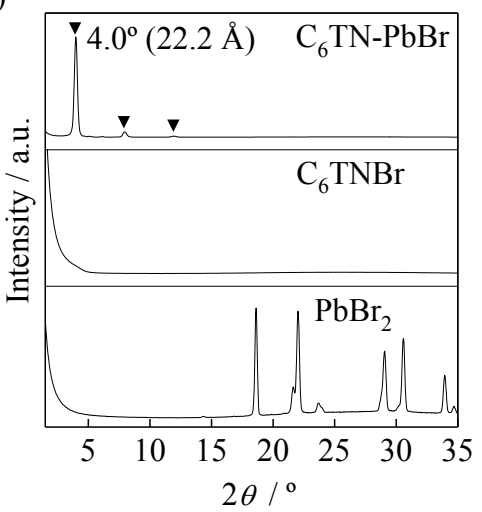

(b)

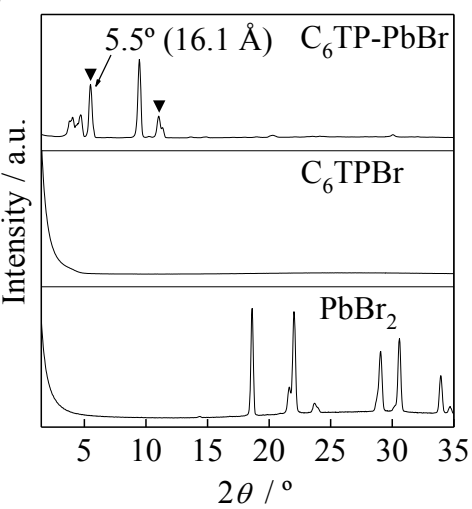

Fig. S1 Out-of-plane XRD profiles of films: (a) $\mathrm{C}_{6} \mathrm{TN}-\mathrm{PbBr}, \mathrm{C}_{6} \mathrm{TNBr}$ and $\mathrm{PbBr}_{2}$ and (b) $\mathrm{C}_{6} \mathrm{TP}-\mathrm{PbBr}, \mathrm{C}_{6} \mathrm{TPBr}$, and $\mathrm{PbBr}_{2}$. 